\title{
Teacher's manual and method for SD integration in curricula
}

\author{
K. Ceulemans*, M. De Prins \\ Hogeschool-Universiteit Brussel, Centre for Corporate Sustainability, Stormstraat 2, B-1000 Brussels, Belgium
}

\section{A R T I C L E I N F O}

\section{Article history:}

Received 11 February 2009

Received in revised form

25 August 2009

Accepted 12 September 2009

Available online $\mathrm{xxx}$

\section{Keywords:}

Sustainability in higher education

Curricula

Teacher training

\begin{abstract}
A B S T R A C T
Although teaching sustainability issues is considered a difficult task, teachers are at the centre of curriculum renewal when directing it more towards sustainability. This article presents a teacher's manual and method for the integration of SD in curricula of higher education as well as an evaluation of their use. The manual is a powerful tool that combines a focus on teacher's capacities for SD integration within their discipline with student-activating teaching methods. Even in institutions where management support is low, it is a valuable means. Because of its generality and flexibility, the method appears to be of great potential as a framework for SD integration.
\end{abstract}

(c) 2009 Elsevier Ltd. All rights reserved.

\section{Introduction}

The United Nations Decade of Education for Sustainable Development (UN DESD) has directed attention to the integration of sustainable development (SD) in all educational settings [1]. For higher education, SD integration can traditionally be situated on different levels, i.e. education, research, university operations and external community [2-4]. This article focuses on the first level: the integration of SD in education, or also curricula. The discussion on this topic is lively and ongoing. As Boks and Diehl [5] state, a body of knowledge and experience is beginning to develop on the subject, yet according to the authors, 'this body mainly reports on experiences with teaching separate courses devoted to sustainability topics'. In general, two tendencies can be distinguished in literature regarding SD integration in curricula: horizontal or vertical integration. In horizontal integration, SD is interwoven within different courses of the curriculum, while vertical integration can be understood as the organization of separate SD courses within the curriculum. Although both options have their own advantages and disadvantages, many authors and institutions (among which Juárez-Nájera et al. [6], Peet et al. [7], Roorda [8], UNESCO [9] and Wals \& Jickling [10]) are clearly in favor of horizontal integration. They all focus on interdisciplinarity and the necessity of a systemic and holistic approach towards SD.

Lozano [11] reports on four approaches for the incorporation of SD:

\footnotetext{
* Corresponding author. Tel.: +32 26098277.

E-mail address: kim.ceulemans@hubrussel.be (K. Ceulemans).
}

1. Some coverage of some environmental issues and material in an existing module or course;

2. A specific SD course;

3. SD intertwined as a concept in regular disciplinary courses, matching the nature of each specific course;

4. SD as a possibility of specialization within the framework of each faculty.

According to the author, these approaches are sometimes used independently, while other authors combine them. Both the vertical integration (approach 2) and the horizontal integration approach (approach 3 and 4) can be identified in Lozano's [11] enumeration. Lozano and Peattie (2007 in [11]) state that intertwining SD as a concept in regular courses (approach 3 ) is the most promising approach for students to integrate SD and its principles in their future professional lives.

Teaching about SD concepts has often been experienced as a difficult task [12]. According to Lidgren [13], the main obstacles are the limited frame of reference of the teachers, the multidisciplinary character of research related to sustainability, the misunderstanding of sustainability inclusion, the workload of teachers and the fact that sustainability is not seen as a core issue. Many teachers are not familiar with the concepts of SD. Moreover, most of them are unaware of the meaning of SD to specific disciplines [7]. It is essential to firstly address this problem when horizontally incorporating SD into curricula. Lidgren et al. [3] state that 'when this is done, they [teachers] can start to examine their curricula for existing contributions to $S D$ '. Besides the problem of lack of knowledge of teachers, the general lack of awareness of the importance of education for sustainable development (ESD) is another important difficulty [14]. 
As a result, it appears to be easier to engage teachers who are already interested in or committed to SD integration in their courses [15]. The methods on how to achieve an integration of SD in education are often unclear to education staff members [16]. Nevertheless, teachers are at the centre of curricular development when directing it more towards sustainability, because they are responsible for the introduction of the subject of SD to their students [17]. Mohamedbhai [18] indicates that 'higher education institutions need to train teachers who are sensitized for promoting SD in schools, and develop school curricula which incorporate SD'. UNESCO also recognizes teacher training as a key strategy in achieving a sustainable society [15]. Teacher training does not only involve the education of new teachers (or pre-service training) [15], it is also directed at updating the knowledge and skills of in-service teachers [19]. Furthermore, 'educating the educators' is part of Lozano's [20] five major steps to take to incorporate SD into the university system. Holmberg et al. [21] also consider the availability of skilled teachers in the institution as one of the success factors for SD integration in curricula.

Although the UN DESD has focused some attention on ESD, often teachers are unaware of the availability of teaching materials and they are also often not well prepared to integrate SD in their courses $[17,22,23]$. Yet, several methods and approaches for the incorporation of SD in higher education - both in in-service and pre-service teacher training - are available. Some of these are presented in the following. Fien and Maclean [24] report on two teacher education projects from Asia and the Pacific. They stress the need for 'teacher educators to ground their work in an ecological approach which integrates curriculum development, professional development and reflective practitioner-based research'. The Dutch organization for Sustainable Higher Education - Duurzaam Hoger Onderwijs (DHO) in Dutch - started in 2000 with the publication of disciplinary reviews on SD. These reviews are intended as a substantive and methodological supporting tool for SD integration in curricula. Peet et al. [7] indicate that for SD integration in curricula 'an individual, consultant-like approach is most promising, as it does not conflict with academic culture, keeps the lecturer in charge of his or her own courses and acknowledges the specifics of each subject'. Therefore, the authors started up individual conversations with teachers to reveal SD related subjects in disciplinary courses applying this consultant-like approach, called the Individual Interaction Method (IIM). A similar approach was also used by Gayford [25] for the integration of SD in secondary curricula in England, where it was important for the researcher to maintain a low profile and act as a facilitator for SD integration, rather than leader or expert. At the university of Monterrey, Mexico [26], two faculty training courses were developed: an initial three-day course which focuses on the concepts inherent in the Triple Bottom Line and a new, integrated 'Educate-the-Educator's' course which consists of six modules.

Although a wide variety of SD integration methods and approaches exist, the Hogeschool-Universiteit Brussel (HUB) detected the need for a teacher's manual for the integration of SD in student curricula. The manual and method promote a horizontal approach of SD integration in existing disciplinary courses corresponding to Lozano's [11] third approach. Nevertheless, in order to achieve a more integrated approach towards SD integration in subject disciplines, additional links and cooperation between different disciplinary courses are aimed for, like Gayford [25] suggested. In the following section the manual and the method are presented.

\section{HET IVOOR: project on CSR integration in curricula}

The manual and method for SD integration in curricula were developed by the HUB in a project called 'HET IVOOR', a Dutch acronym for 'manual and training for the integration of corporate social responsibility (CSR) in higher education'. The HUB is an atypical Belgian higher education institution that arose from a merger of a university and three colleges. This institution therefore disposes of characteristics of both types, e.g. it is research-based but also focuses on education-centered activities. Since academic year 2005-2006, the management of the HUB put SD on the agenda of the institution, resulting in a vision, strategic and operational commitments and clear SD objectives. The project 'HET IVOOR' was initiated by the sustainability coordinator of the institution, though (financially) supported by both the management of the institution and the European Social Fund (ESF). For the project, a full time coordinator was recruited.

The 18 month project HET IVOOR focused on the curriculum of commercial engineers. The Bachelor (three years) and Master (two years) in Commercial Engineering is a unique academic program in Belgium in which economists are skilled with applied sciences in order to become a bridging person between pure economists and (industrial or civil) engineers. The project team decided to concentrate on commercial engineering students, because they are future managers who will be able to create different business environments in the distant future. Therefore, it is important that these students know about SD concepts and are able to integrate them into business strategy, economics, corporate finance, marketing etc. [27]. In order to achieve this, it is essential to train teachers and provide them with specific knowledge on the subject of SD, as was stated before. For this training, a teacher's manual was set up by the project team of HET IVOOR and cooperating teachers.

The manual is a self-instructional in-service teacher training tool, providing teachers with guidelines on the integration of CSR in curricula. It consists of approaches for the integration of CSR in courses and not SD, because the manual is directed at commercial engineering teachers and CSR is a concept that is more closely related to their discipline than SD. The translation to CSR makes it easier for teachers to situate SD relative to their own practices [28]. UNESCO's [19] 'Guidelines and Recommendations for Reorienting Teacher Education to Address Sustainability' also stresses that it is important to use the vocabulary of the audience you are communicating with and to find out what they are interested in and link their passions (in this case business and management principles) to SD.

\subsection{Presentation of the teacher's manual}

The teacher's manual of HET IVOOR consists of different parts and chapters, presented in Table 1 . After a short introduction, parts

Table 1

Parts and chapters of the teacher's manual for the integration of CSR.

\begin{tabular}{l}
\hline Introduction \\
1. Project with funding from the European Social Fund \\
2. Acknowledgements \\
Part 1: SD and CSR \\
1. What is SD? \\
2. What is CSR? \\
3. Why sustainable entrepreneurship? \\
Part 2: SD and CSR in Education \\
1. SD and CSR in education \\
2. Competences for SD and CSR \\
Part 3: Relationship between CSR and Disciplines \\
1. Introduction \\
2. Relationship between CSR and Higher Education courses \\
3. Relationship between CSR and Professional Education courses \\
Part 4 : Integration of CSR: Teacher Materials \\
1. Introduction \\
2. Overview of student-activating teaching methods \\
3. Teacher materials for CSR in Higher Education \\
4. Teacher materials for CSR in Professional Education \\
Appendix: Student-activating Teaching Methods
\end{tabular}


Table 2

Appendix: Student-activating Teaching Methods.

\author{
Introduction \\ Videos \\ Brainstorming \\ Case method \\ Demonstration \\ Forms of dialogue \\ Team work \\ Jigsaw \\ Assignments \\ Problem-oriented education \\ Oral presentation \\ Project learning \\ Small discussion groups \\ Voting \\ Questions
}

1 and 2 provide the reader with definitions and additional information on SD, ESD and CSR. The first two chapters of part 1 deal with the definitions of the concepts of SD and CSR, while in chapter 3 , the benefits of sustainable entrepreneurship are addressed. This should provide an answer to the fact that many people think that the concept of SD is too abstract (Filho, 2000 in [23]) and that they are unaware of the advantages of CSR and wonder whether companies themselves benefit from a higher degree of corporate responsibility. In part 2, focus is set on SD and CSR in education. Here, the milestones of SD and education are presented, and some examples are given on local SD initiatives in Belgium and the Netherlands. The second chapter of part 2 is dedicated to student competences for SD and CSR. In this chapter, the desired learning outcomes for students related to SD and CSR are expressed, which is valuable for reasons of comparability and for the ability to explicitly express the required learning regarding SD [29].

Part 3 addresses the relationship between CSR and different disciplines. For a number of courses in different disciplines, a text and table were set up, in which the major links with CSR are indicated. The final part is a compilation of teaching methods, routines and exercises for the integration of CSR into different disciplines included in the commercial engineering program. Specific exercises for teachers were created in order for them to gain inspiration on the practical integration of the subject into curricula. For example, exercises on management accounting, chemistry, economics, logistics, physics and marketing are present in part 4 of the manual. In order for students to develop an interest in sustainability issues, not solely the content of a course is important, the teaching style should also be varied [30]. Therefore, focus was not set on formal lectures, but on CSR integration in student-activating teaching methods and exercises. The project team thereby acknowledged the fact that SD integration in curricula requires a reorientation of teaching approaches and methodologies, so that team work, multiand interdisciplinary collaboration and project-based initiatives could be set up $[6,18]$. For teachers who are not familiar with student-activating methods, an appendix on this subject was added to the manual. The content of the appendix is listed in Table 2 .

As is shown in this section, the teacher's manual combines general and discipline related SD background information with student-activating teaching materials. As a consequence of the

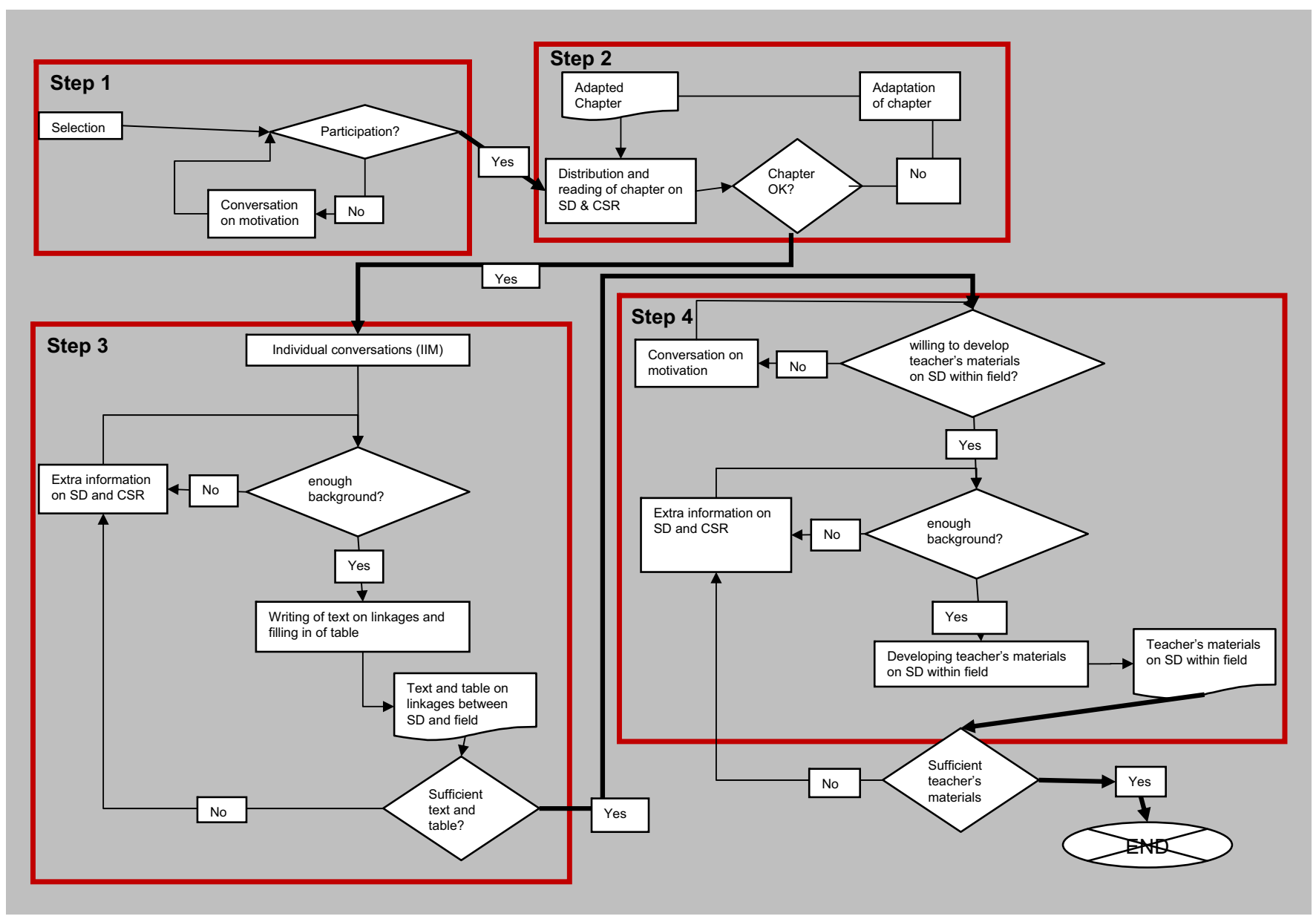

Fig. 1. Process flow of the four-step method for the development of the teacher's manual. 
structure and subjects of the manual, it forms a self-contained instruction book for teachers on SD integration in which they can deduce those parts and chapters that are relevant for them.

\subsection{Presentation of the method}

Besides being a direct outcome of the project, the manual also functioned as a means for the development of a general method for SD integration. The overall purpose of the method is to develop a teacher's manual while simultaneously motivating all teachers in an informal and non-compulsory way to integrate relevant SD topics into their courses and apply student-activating teaching methods. In an educational institution, one is confronted with teachers with different strengths, dispositions and priorities [31], also on the level of SD knowledge or teaching styles. This requires varying combinations of approaches towards SD integration, taking into account different backgrounds and education of the involved teachers [17]. Consequently, in order to convince different types of teachers to cooperate, a flexible four-step method for SD integration was developed by the project team of HET IVOOR.

Fig. 1 presents the process flow of the four-step method that was used to create the teacher's manual. First of all, the introduction, part 1 and part 2 of the manual - as shown in Table 1 - were written by the project coordinators. The project team decided that the third and fourth part of the teacher's manual should be written by teachers themselves. The reason for this decision was that (1) as teachers are experts in their disciplines, they were best placed to supply the information and (2) this would be an excellent opportunity to involve them in the ESD agenda. As a first step of the process flow, teachers were selected and asked to participate in the project. The teachers were selected if the project team was of the opinion that there was an interesting opportunity for SD integration in their courses. The selected teacher group was very heterogeneous: some of them already devoted some of their time to SD integration in their courses, while others - the majority of the teachers - did not yet spend any attention to SD integration in their courses. If a teacher decided to participate in the project, he or she was handed over the first chapters of the manual in order to gain insight into the concepts of SD and CSR. This approach was also an indication of the practicability of the first chapters for the project group. If the teachers doubted the usefulness of the project and their ability to participate, a member of the project team attempted to convince them during a one-on-one conversation. At the beginning of the third step of the process flow, the IIM [7] was partially applied. Individual, informal conversations with teachers were set up, in order to assess their knowledge on SD and CSR, to - if necessary provide them with extra information on both subjects, and to jointly search for specific links between CSR and their discipline. The aim of the conversation was to reveal possible links with CSR that are already present in the course, and to examine new possibilities for CSR integration in courses. For the detection of links between scientific disciplines and SD, the IIM has proven to be quite successful [21], hence this could also be the case for finding links between disciplines and CSR. Consequently, in collaboration with the project team, the conversations resulted into the formulation of a text - analogously to the disciplinary reviews of DHO, but limited in length - pointing out the links of the discipline with CSR. To this text, a table was added in which a number of specific CSR concepts were drawn up. For each of these concepts, the teachers were asked to mark the links of the concepts and their discipline with an ' $\mathrm{X}$ ', and add a sentence or notion to further explain the relationship. The concepts marked in the table are equivalent to the ones in the text, but they provide a quick visual image of the revealed links. Table 3 shows a blank table, as it was presented to the teachers.
When both parties were satisfied with the quality of the text and tables, the last step of the process flow was conducted. The teachers were asked to cooperate on finding new didactic materials for CSR integration in their courses. As a result, either completely new CSR related routines, methods and exercises were drawn up, either existing exercises were adapted by adding components of CSR. Finally, some teachers who were already in the process of utilizing SD integrated teaching materials were asked to share their work with interested colleagues and give permission for their work to be added to the manual as best practices.

\section{Evaluation and discussion of the teacher's manual and the SD integration method}

The teacher's manual and SD integration method were evaluated by the project team and different stakeholders - internal and external persons to the project - both during the project as well as

Table 3

Links between CSR and discipline.

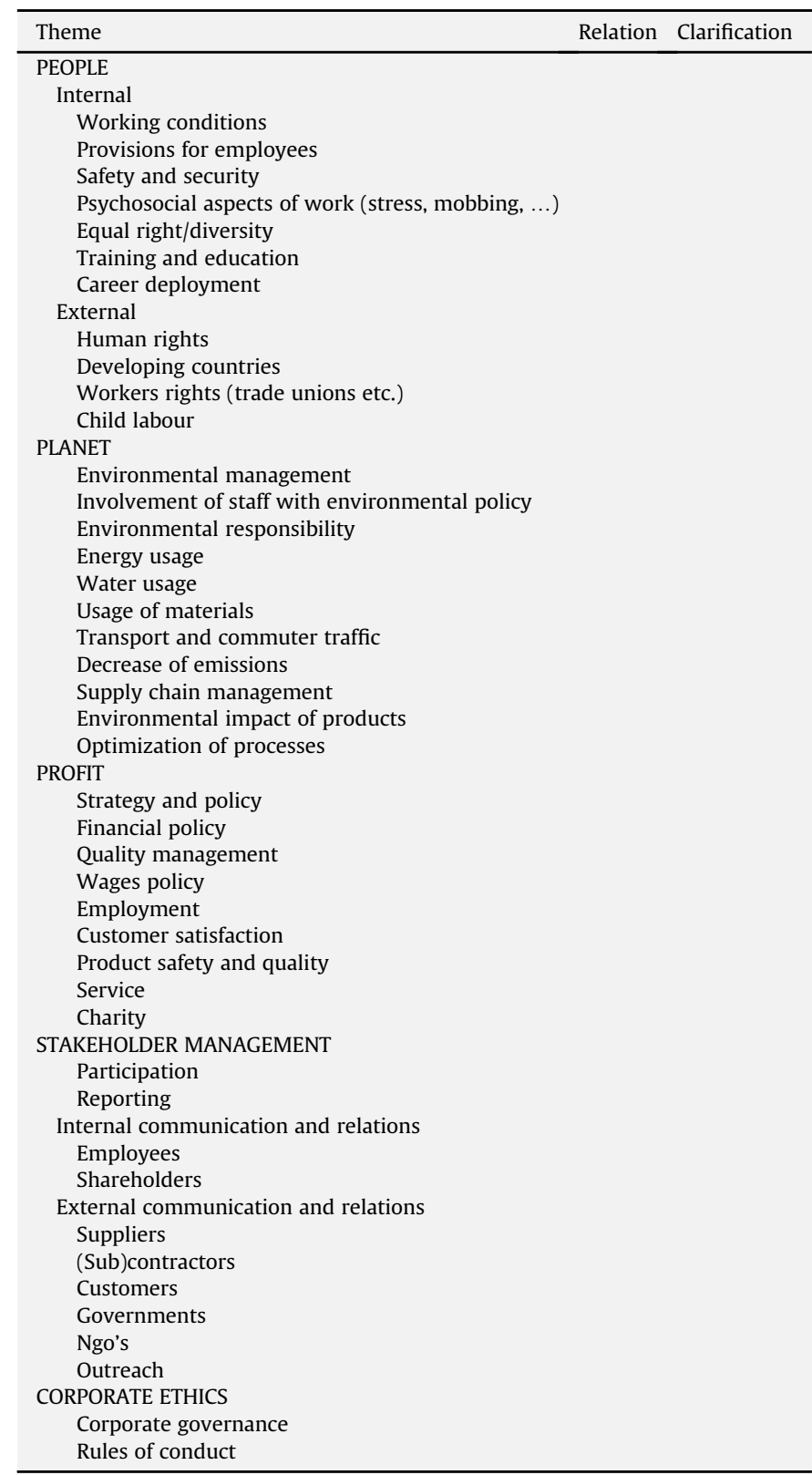


after its termination. Throughout the project, it was evaluated by and adjusted according to the directions of a steering committee, which was composed of relevant NGOs. After the termination of the project, it was evaluated by ESF. The project coordinator also executed in-depth interviews with several users of the manual from different types of institutions.

\subsection{The manual}

The project team received specific comments on the usefulness and practicality of the manual from teachers of different higher education institutions and other stakeholders. The interviews revealed that the parts of the manual are not equally ranked: it is mainly part 4 - the ready-to-use didactic materials for SD integration - that was evaluated as very useful for teachers. An important issue for the interviewed teachers is that the didactic materials are thoroughly specified, so that they are instantly applicable in the classes, without major adaptations being necessary. The interest for didactic materials which require further adaptation by teachers is lower, often due to lack of time or because some teachers do not see themselves as an expert in the field of SD. The appendix was also highly valued by the interviewees because of its focus on alternative teaching methods which are often unknown or not used by them.

Part 1 and 2 of the manual, the introduction to the concepts of SD, ESD and CSR, were considered useful because of the very practical outline (not too specialized or scientific) of these concepts. Teachers who are familiar with SD/CSR concepts claim that the introductory parts are a solid induction for novices. Although part 3 provides discipline related CSR subjects as a logical and necessary transition from pure CSR concepts to discipline related didactic materials, this part was ranked as the least valuable for teachers. The interviews disclosed that teachers seem to be mainly interested in ready-to-use exercises and in that regard, part 3 is too vague for direct application in their classes. Also, there was no unanimity about the terms to be included in the table included in part 3. Nevertheless, the terms in the table were thoroughly discussed and adapted by the steering committee during the development of the manual.

At first glance, the evaluation of the manual reveals the same barrier as presented by Lidgren [13], i.e. lack of time, but the respondents confirmed that here this barrier was overcome by the development of ready-to-use exercises and by the manual's selfinstructional form, giving the opportunity to teachers to move from one part to another. The self-contained form of the manual was also considered important because of the difference in knowledge and understanding of SD subjects among teachers.

The horizontal, disciplinary approach towards SD integration used in the manual (analogous to Lozano's [11] approach 3) should mainly be seen as a starting point for SD integration in the institution. Although different authors stress the disadvantages of disciplinary work regarding to SD integration (e.g. Elshof [32], Sibbel [33]), the conversations with different teachers pointed out that at this moment, there is mainly a need for specific didactic materials within the disciplines, rather than to reorient the entire education system towards SD. The integration efforts should nevertheless pay attention to student-activating teaching methods, due to their advantages in terms of recall as compared to traditional lectures and to possibilities for integration between different disciplinary courses (analogously to Gayford [25]). The horizontal approach is also more closely related to training of educational staff than the vertical one: the vertical approach does not require training of all teachers, since integration happens through a separate SD course in the curriculum.

As a recommendation for the project team, different stakeholders suggested the use of the internet for the dissemination and exchange of new didactic materials. The manual is entirely and freely available online in Dutch on www.competento.be/ivoor.aspx, yet no interactive tools for exchange of didactic materials are included on the website. The problem is that teachers are interested in inputs on the improvement on their classes, but in spite of that, they are often not willing to pass on their own didactic materials to others. This is due to the fact that they do not feel an expert in the SD subject and therefore they are very critical towards (the availability of) their own materials. Nevertheless, in order to keep the manual up-to-date and to ensure its future use, new materials should be added from time to time.

\subsection{The method}

The entire four-step method was very valuable for the project team as a framework for SD integration in the institution, because of the incremental and voluntary manner of integration. The method managed to involve many teachers of the institution on the SD agenda. The cooperation between the project team and teachers also created a dialogue on SD integration in curricula and broadened their knowledge and visions on the complex concepts of SD and CSR.

The use of this method should not be limited to the HUB or to commercial engineering curricula: it can also be applied in other academic programs and educational institutions as a generic approach for SD integration in their curricula. However, in that case, the manual should be translated to the specific context of the academic program (e.g. other scientific disciplines should be involved). Like CSR is a concept related to commercial engineering, a similar concept could be sought for SD integration in other academic programs. An adaptation of the SD integration method to the local context of the involved institutions is also a prerequisite [21]. This is due to the fact that no two institutions are completely alike, and that therefore an individual system should be implemented that is locally relevant and culturally appropriate [34]. UNESCO [19] also stresses that best practices of teacher materials on SD integration should only be shared around the world when they are adapted and modified to the local context in the institutions.

While disseminating the project, the method was presented and some parts of it were used in a workshop. The workshop and its evaluation confirmed that the method is transferable to other institutions and settings. Still, up until now, the project team has no knowledge of the adoption of this method. Most likely this is due to the high costs of the method. A disadvantage of this method is that it requires the appointment of a facilitator for SD integration, necessitating available time and financial means from the institution. The method of integration also requires a large effort and commitment from the teaching staff, which is often difficult due to lack of time. Despite the considerable investment of time, the results will possibly not be immediately visible in the institution because of the horizontal integration.

\subsection{Added value}

Until now, there is no single, generic and universal method available to ensure successful integration of SD in curricula. Yet it is important to gain the knowledge that is documented in other best practices and use this for the development of new methods for SD integration. The teacher's manual and method of HET IVOOR was thought of in this way, by bundling existing methods with innovative elements.

The method developed in HET IVOOR facilitates the SD integration process through dialogue, voluntary cooperation and involvement by teachers. This method excellently fits an incremental integration as Lozano [20] suggests.

The manual is a powerful tool that combines the strong elements of the IIM, focusing on teachers' knowledge for SD 
integration within their discipline, with practical and ready-to-use exercises, while applying student-activating teaching methods. Teachers can freely make adaptations or additions to their classes in order to orient them more towards SD. Through the manual, they receive didactic materials that are thoroughly specified, so that they are instantly applicable in the classes, without major adaptations being necessary. On the other hand, they can also be challenged and inspired by the examples provided by the manual and create their own exercises, examples or case studies.

Another advantage of the manual is that in institutions where there is little or no management support for SD integration, interested teachers can take their own responsibility and integrate SD aspects in their courses on an individual basis. Although a profound horizontal SD integration requires more efforts and therefore management support, one should realize that not all institutions prioritize SD integration or dispose of budgets to execute such a project. As was found through individual conversations with teachers of different institutions, individual use of the manual is often a starting point for SD integration in their own specific course within the institution. Because of the structure of the manual, teachers can freely choose which topics to integrate and which teaching methods they will use. The self-instructional approach also implies that the manual becomes suitable for teachers with different backgrounds on SD, as they can deduce the manual to the necessary parts and chapters.

As a last novelty, one could say that a manual like this can be used to involve both in-service as pre-service teachers. For teachers that are new to the institution, one can provide for a starting package of relevant documents in which the manual is included, while for other teachers, the manual can be kept available at the institution.

\section{Conclusions}

This article has presented a manual and method towards SD integration in curricula, developed by the HUB. The unique character of the manual and method can mainly be situated in the combination of approaches and the emphasis on both the SD related content and the methods in which these elements can be taught. Other advantages and novelties as compared to existing manuals is (1) the fact that the manual is self-instructional, giving a lot of freedom to the teachers using it, (2) the possibility to use it individually, regardless of SD background and even without management support, and (3) the suitability for both pre- and inservice teacher training. The method adopted in HET IVOOR is also not solely useful for the HUB and for commercial engineering curricula: when specific adaptations are made, they become relevant for other institutions in their local contexts or other academic programs.

As far as the project team is informed, up to the write-up of this article, no new manual for other institutions or academic programs has yet been developed, although in Belgium and abroad, there has been shown some interest to do this. Often the necessary financial means are lacking to finalize the entire project. For the project team, it would be interesting to be kept informed on possible development of similar teacher manuals in other institutions, for reasons of exchange of experiences and knowledge.

\section{Acknowledgements}

The project partners would like to thank ESF (www.esfagentschap.be) for their funding and belief in the prospects of ESD in Higher Education. All cooperating education staff members are acknowledged for various inputs to the texts, didactic materials and evaluation of the teacher's manual.

\section{References}

[1] Calder W, Clugston R. Education for a sustainable future. Journal of Geography in Higher Education 2005;29(1):7-12.

[2] Cortese AD. The critical role of higher education in creating a sustainable future. Planning for Higher Education 2003;31(3):15-22.

[3] Lidgren A, Rodhe H, Huisingh D. A systemic approach to incorporate sustainability into university courses and curricula. Journal of Cleaner Production 2006;14:797-809.

[4] Velazquez L, Munguia N, Platt A, Taddei J. Sustainable university: what can be the matter? Journal of Cleaner Production 2006;14:810-9.

[5] Boks C, Diehl JC. Integration of sustainability in regular courses: experiences in industrial design engineering. Journal of Cleaner Production 2006;14:932-9.

[6] Juárez-Nájera M, Dieleman H, Turpin-Marion S. Sustainability in Mexican Higher Education: towards a new academic and professional culture. Journal of Cleaner Production 2006;14:1028-38.

[7] Peet D-J, Mulder KF, Bijma A. Integrating SD into engineering courses at the Delft University of Technology. The individual interaction method. International Journal of Sustainability in Higher Education 2004;3. 278-288.

[8] Roorda N. AISHE: auditing instrument for the integration of sustainability in higher education. Amsterdam: DHO; 2001.

[9] UNESCO (2008). United Nations EducationalScientific and Cultural Organization. Education - welcome to education for sustainable development. Retrieved July 4, 2008, from, http://portal.unesco.org/education/en/ev.phpURL_ID $=27234 \&$ URL_DO $=$ DO_TOPIC\&URL_SECTION $=201 . \mathrm{html}$.

[10] Wals AEJ, Jickling B. Sustainability in higher education: from doublethink and newspeak to critical thinking and meaningful learning. Higher Education Policy 2002;15:121-31.

[11] Lozano R. Diffusion of sustainable development in universities' curricula: an empirical example from Cardiff University. Fifth international EMSU conference. Barcelona, Spain: Environmental Management for Sustainable Universities; 2008.

[12] Steiner G, Posch A. Higher education for sustainability by means of transdisciplinary case studies: an innovative approach for solving complex, realworld problems. Journal of Cleaner Production 2006;14:877-90.

[13] Lidgren A. A sustainable course for higher education. MSc thesis 2004. Retrieved from http://www.iiiee.lu.se/Publication.nsf/\$webAll/14E0DB35970472A7C1256F9D00527E97/\$FILE/Alexander\%20Lidgren.pdf.

[14] Shallcross T, Robinson J. Introduction. Is a decade of teacher education for sustainable development essential for survival? Journal of Education for Teaching 2007;33(2):137-47.

[15] Ferreira J-A, Ryan L, Tilbury D. Mainstreaming education for sustainable development in initial teacher education in Australia: a review of existing professional development models. Journal of Education for Teaching 2007;33(2):225-39.

[16] Stir J. Restructuring teacher education for sustainability: student involvement through a strengths model. Journal of Cleaner Production 2006;14:830-6.

[17] Martins AA, Mata TM, Costa CAV. Education for sustainability: challenges and trends. Clean Technologies and Environmental Policy 2006;8:31-7.

[18] Mohamedbhai G. Contribution of higher education to the UN millennium development goals. In: Higher education in the World 3, higher education: new challenges and emerging roles for human and social development. Global University Network for Innovation (GUNI). Hampshire: Palgrave Macmillan; 2007.

[19] UNESCO. Guidelines and Recommendations for Reorienting Teacher Education to Address Sustainability. Education for Sustainable Development in Action. Technical Paper No. 2. Paris: UNESCO; 2005.

[20] Lozano R. Incorporation and institutionalization of SD into universities: breaking through barriers to change. Journal of Cleaner Production 2006;14 787-96.

[21] Holmberg J, Svanström M, Peet D-J, Mulder K, Ferrer-Balas D, Segalàs J. Embedding sustainability in higher education through interactions with lecturers: case studies from three European technical universities. European Journal of Engineering Education 2008;33(3):271-82.

[22] Boyle C. Considerations on educating engineers in sustainability. International Journal of Sustainability in Higher Education 2004;5(2):147-55.

[23] Thomas I. Sustainability in tertiary curricula: what is stopping it happening? International Journal of Sustainability in Higher Education 2004;5(1):33-47.

[24] Fien J, Maclean R. Teacher education for sustainability. II. Two teacher education projects from Asia and the Pacific. Journal of Science Education and Technology 2000;9(1):37-48.

[25] Gayford C. Education for sustainability: an approach to the professional development of teachers. European Journal of Teacher Education 2001;24(3): 313-27.

[26] Lozano FJ, Huisingh D, Perni O, Hernández DE, Gándara G, Manzano M. Lessons derived during the development and testing of an Educate-the-Educator's capacity building program on Sustainable Development in Monterrey Tec in Mexico. Fourth International EESD Conference. Engineering Education in Sustainable Development, Graz, Austria; 2008.

[27] Stubbs W, Cocklin C. Teaching sustainability to business students: shifting mindsets. International Journal of Sustainability in Higher Education 2008; 9(3):206-21.

[28] Elshof L. Teacher's interpretation of sustainable development. International Journal of Technology and Design Education 2005;15:173-86. 
[29] Segalàs J, Ferrer-Balas D, Svanström M, Lundqvist U, Mulder KF. What has to be learnt for sustainability? A comparison of bachelor engineering education competences at three European universities. Sustainability Science 2009;4(1): 17-27.

[30] Warburton K. Deep learning and education for sustainability. International Journal of Sustainability in Higher Education 2003:4(1):44-56.

[31] James M, McCormick R. Teachers learning how to learn. Teaching and Teacher Education 2009;25:973-82.
[32] Elshof L. Technological education, interdisciplinarity, and the journey toward sustainable development: nurturing new communities of practice. Canadian Journal of Science, Mathematics and Technology Education 2003; 3:165-84.

[33] Sibbel A. Pathways towards sustainability through higher education. International Journal of Sustainability in Higher Education 2009;10(1):68-82.

[34] Fien J. Advancing sustainability in higher education: issues and opportunities for research. Higher Education Policy 2002;15:143-52.

Please cite this article in press as: Ceulemans K, De Prins M, Teacher's manual and method for SD integration in curricula, J Clean Prod (2009), doi:10.1016/j.jclepro.2009.09.014 